\author{
G. S. Mijnhout • P. Scheltens • M. Diamant • \\ G. J. Biessels • A. M. Wessels · S. Simsek • F. J. Snoek • \\ R. J. Heine
}

\title{
Diabetic encephalopathy: a concept in need of a definition
}

Received: 30 January 2006 / Accepted: 1 February 2006 / Published online: 6 April 2006

C) Springer-Verlag 2006

Diabetes mellitus is associated with the occurrence of welldescribed microvascular complications, including retinopathy, nephropathy and peripheral neuropathy. The concept of central neuropathy has been controversial for more than 80 years now. As early as 1922 it was recognised that diabetes can lead to cognitive dysfunction [1]. The prevalence of cognitive dysfunction is difficult to estimate as it depends heavily on the way it is assessed. The reported prevalence is about $40 \%$ in long-standing or poorly controlled diabetes [2]. Cognitive dysfunction in diabetes is characterised by lowered performance on several cognitive domains, most notably slowing of mental speed and diminished flexibility [3]. The magnitude of these cognitive deficits appears mild to moderate, but can significantly hamper daily functioning, adversely affecting quality of life [4]. Cognitive decline in diabetic patients treated with insulin has so far largely been attributed to recurrent episodes of hypoglycaemia, rather than to hyperglycaemia, although there is little evidence to support

G. S. Mijnhout - M. Diamant · S. Simsek · R. J. Heine

Department of Endocrinology and Diabetes,

VU University Medical Centre,

Amsterdam, The Netherlands

P. Scheltens

Department of Neurology, VU University Medical Centre, Amsterdam, The Netherlands

A. M. Wessels · F. J. Snoek Department of Medical Psychology,

VU University Medical Centre,

Amsterdam, The Netherlands

G. J. Biessels

Department of Neurology, University Medical Centre, Utrecht, The Netherlands

G. S. Mijnhout $(\bowtie)$

Department of Endocrinology, VU University Medical Centre, P.O. Box 7057, 1007 MB Amsterdam, The Netherlands e-mail: gs.mijnhout@vumc.nl

Tel.: +31-20-4441016

Fax: +31-20-4440502 this notion $[5,6]$. In trying to describe cognitive impairment in diabetes as a complication of the disease, the term 'diabetic encephalopathy' was introduced in 1950 [7]. In 1965, rather characteristic pathological changes were found in brains from 16 long-term juvenile diabetic patients who had died from vascular complications of diabetes [8]: diffuse degenerative abnormalities, pseudocalcinosis, severe angiopathy of cerebral vessels, atrophy of the dentate nucleus, demyelinisation of cranial nerves and fibrosis of the leptomeninges. The authors stated that this histological pattern justifies the term 'diabetic encephalopathy', because it differs from that seen in any other clinical condition. However, for several reasons, the term 'encephalopathy' has not been widely accepted. Firstly, it has strong negative connotations and does not seem to match the mild cognitive problems usually seen in (nondemented) diabetic patients. Secondly, and most importantly, the diagnosis diabetic encephalopathy lacks clear criteria and is therefore difficult to ascertain. Historically, the term diabetic encephalopathy applies to type 1 diabetic patients only. Other terms found in the literature to describe cognitive dysfunction in diabetes include functional cerebral impairment and central neuropathy. To facilitate research into this area and to increase recognition of the disorder, we propose a new term-'diabetes-associated cognitive decline' (DACD). This term is not suggestive of a particular pathogenesis, but merely describes a state of mild to moderate cognitive impairment, in particular psychomotor slowing and reduced mental flexibility, not attributable to other causes. Pathogenic research should focus on type 1 diabetes patients first, as in type 2 diabetes bias is introduced by several coexistent risk factors for cognitive dysfunction other than hyperglycaemia (e.g. hypertension, hyperlipidaemia). For further validation of the term DACD, we propose the operational research criteria summarized in the text box. As the relation between cognitive complaints and objective dysfunction is weak, we do not regard subjective complaints about cognitive functioning as a prerequisite for diagnosis of DACD. As cognitive dysfunction in type 1 diabetes is usually mild to 
moderate [3], we chose a performance $>1.5 \mathrm{SD}$ below that of controls as a criterion for DACD. Future research may refine the currently proposed criteria.

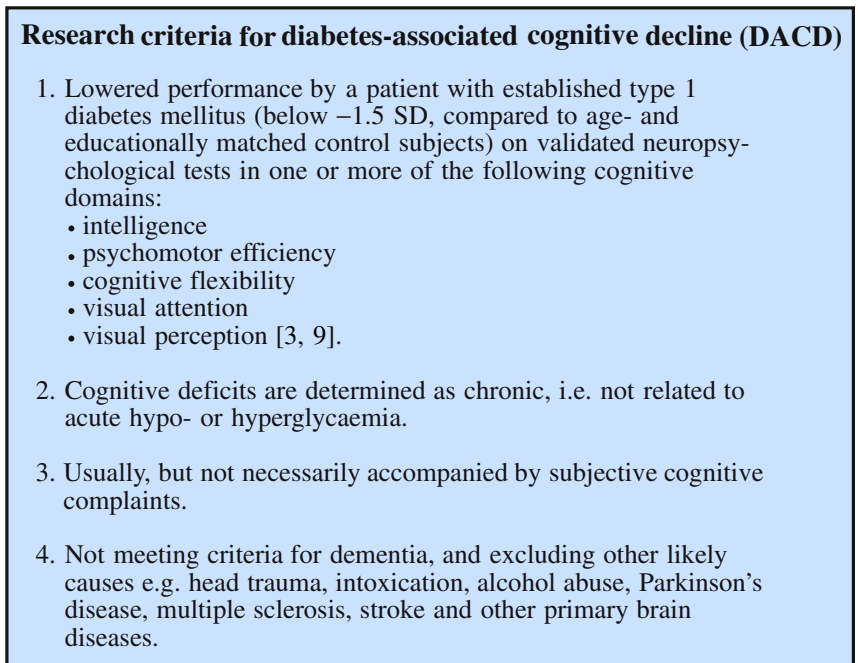

We hope that by offering this simple descriptive definition, research into the pathogenesis, consequences and potential therapeutic interventions of DACD will be stimulated. In addition, the extent to which diabetes-related cognitive decline affects day-to-day functioning and diabetes self-care needs to be assessed, to further expand our understanding of the clinical implications of this poten- tially burdensome complication. The reliability of this assessment is fully dependent on the accuracy of the diagnostic tests.

\section{References}

1. Miles WR, Root HF (1922) Psychologic tests applied in diabetic patients. Arch Intern Med 30:767-770

2. Dejgaard A, Gade A, Larsson H, Balle V, Parving A, Parving $\mathrm{HH}$ (1991) Evidence for diabetic encephalopathy. Diabet Med $8: 162-167$

3. Brands AMA, Biessels GJ, de Haan EHF, Kappelle LJ, Kessels RPC (2005) The effects of type 1 diabetes on cognitive performance. Diabetes Care 28:726-735

4. Sinclair AJ, Girling AJ, Bayer A (2000) Cognitive dysfunction in older subjects with diabetes mellitus: impact on diabetes selfmanagement and use of care services. Diabetes Res Clin Pract 50:203-212

5. Deary I, Frier BM (1996) Severe hypoglycemia and cognitive impairment in diabetes: link not proven. Br Med J 313:767-780

6. Austin EJ, Deary IJ (1999) Effects of repeated hypoglycemia on cognitive function. A psychometrically validated reanalysis of the Diabetes Control and Complications Trial data. Diabetes Care 22:1273-1277

7. De Jong RN (1950) The nervous system complications in diabetes mellitus with special reference to cerebrovascular changes. J Nerv Ment Dis 111:181-206

8. Reske-Nielsen E, Lundbaek K, Rafeisen QJ (1965) Pathological changes in the cerebral and peripheral nervous system of young long-term diabetics. I. Diabetic encephalopathy. Diabetologia 1:233-241

9. Lezak MD (1995) Neuropsychological assessment, 3rd edn. Oxford University Press, Oxford 